Revista PSICOLOGIA, 2016, Vol. 30 (1), 49-60. doi: http://dx.doi.org/10.17575/rpsicol.v30i1.1072

\title{
Investigation of the clinical functioning of the Attention Seeking of the Dimensional Clinical Personality Inventory
}

\author{
Lucas de Francisco Carvalho ${ }^{1}$, Catarina Sette ${ }^{1}$, Cláudio G. Capitão ${ }^{1}$ \\ ${ }^{1}$ Universidade de São Francisco, Brasil
}

\begin{abstract}
The aim of this study was to investigate the clinical functioning of one of the dimensions of the Dimensional Clinical Personality Inventory (IDCP), Attention Seeking, and to establish a cutoff considering the diagnosis of histrionic personality disorder, whose pathological characteristics are directly related to this dimension. The IDCP was applied to 1954 participants (62.20\% women), between 18 and 90 years $(M=29.30, S D=11.38)$, divided into three groups: patients with histrionic personality disorders $(n=14)$, patients with other personality disorders $(n=168)$, and those without diagnoses $(n=$ 1772). The parameters of items and persons were estimated by the rating scale model, and reliability measures were generated, as well as the item-person map and map of items, ANOVA for comparison between groups, and ROC curve. The results suggest suitability of the Attention Seek dimension in clinical functioning; however, problems that seem inherent to the histrionic personality disorder were reflected in the setting of the dimension.
\end{abstract}

Keywords: Personality disorders; IRT; Histrionic personality disorder; Personality assessment.

Investigação do funcionamento clínico da dimensão Necessidade de Atenção do Inventário Dimensional Clínico da Personalidade: 0 objetivo deste estudo foi investigar o funcionamento clínico de uma das dimensões do Inventário Dimensional Clínico da Personalidade (IDCP), Necessidade de Atenção, e estabelecer um ponto-de-corte considerando o diagnóstico de transtorno da personalidade histriônico, cujas características patológicas são diretamentes relacionadas a essa dimensão do IDCP. 0 IDCP foi aplicado em 1954 participantes (62.20\% mulheres), entre 18 e 90 anos de idade (M = 29.30; DP = 11.38), divididos em três grupos: pacientes com trantorno da personalidade histriônico $(\mathrm{n}=14)$, pacientes com outros transtornos da personalidade $(n=168)$, e aqueles sem transtornos da personalidade $(\mathrm{n}=1772)$. Os parâmetros dos itens e pessoas foram estimados utilizando o rating scale model, e medidas de fidedignidade foram verificadas, bem como o mapa de itens-pessoas e o mapa de itens, ANOVA para comparação entre grupos, e a curva ROC. Os resultados sugeriram adequação da dimensão Necessidade de Atenção para uso clínico; entretanto, problemas que parecem inerentes ao trantorno da personalidade histriônico foram refletidos no funcionamento da dimensão.

Palavras-chave: Transtornos de personalidade; TRI; Transtorno de personalidade histriônico; Avaliação de personalidade.

Literature indicates that personality disorders (PD) are among the most frequent disorders treated in the psychology and psychiatric clinical practice (APA, 2013; Zuccolo, Corhs \& Savoia, 2013). However, in Brazil, there are still few studies focused on PDs, and the number of instruments aiming to the typical pathological traits of these pathological patterns is limited (Carvalho, Bartholomeu \& Silva, 2010). The present study was developed in this context, focusing on the clinical functioning of one of the dimensions of the Dimensional Clinical Personality Inventory (IDCP), Attention Seeking, which is typically related to the histrionic personality disorder (HPD).

In the Diagnostic and Statistical Manual of Mental Disorders ([DSM-5]; APA, 2013), HPD is defined as a predominant pattern of attention seeking and excessive emotionality. According to the DSM, regarding the diagnostic criteria, individuals diagnosed with this disorder feel uncomfortable when they are not the center of attention, occasionally using physical attributes, i.e., they tend to present excessive seductive and/or overdramatic behaviors. Other features may be present in HPD, such as overreacting, mood swings, in addition to using physical appearance and be dressing to call attention. They have a style of speech that is excessively impressionistic and lacking in detail, show self-dramatization/theatricality, tend to be suggestible, and consider relationships to be more intimate than they actually are.

Still in relation to the HPD diagnostic criteria, Harford et al. (2012) conducted an empirical study

${ }^{1}$ Dados de contacto para correspondência: Lucas Carvalho, Rua Alexandre Rodrigues Barbosa, 45; Centro, Itatiba - São Paulo, Brasil; CEP 13251-90. E-mail: lucas@labape.com.br. 
focusing on the DSM-IV criteria, and observed that the eighth HPD criterion was the most endorsed by the sample $(b=1.50)$ while the fourth was the least endorsed $(b=2.28)$. In that case, we verified that there is a relatively low variance concerning levels of difficulty in the HPD diagnostic criteria, i.e., the criteria for this disorder do not vary much in symptomatic terms.

Based on the diagnostic criteria of the HPD, the literature on the assessment of pathological personality characteristics points out some problems resulting from the diagnosis of this PD. According to Skodol et al. (2011), the frequency of HPD in large clinical samples is extremely variable, making it difficult to estimate their actual prevalence in clinical settings. The prevalence is further questionable when considering the data presented by Widiger (2011), in relation to the number of papers published with each PD, demonstrating that there are many studies, but the HPD is among the least studied. Also in a study referred to as MIDAS project, the HPD was one of the least frequent diagnoses recorded in a sample of 2.151 psychiatric patients (Zimmerman, 2011), demonstrating the low prevalence of this disorder in the clinical sample.

In addition, characteristics present in the diagnosis, such as egocentricity, attention seeking, and emotional lability may also be found in other PDs and other psychiatric disorders, demonstrating the difficulty to differentiate between disorders. Studies such as those by Skodol et al. (2011) indicated the blurring boundaries between the HPD and the borderline PD. High rates of comorbidities in HPD were also pointed out by Zimmerman (2011). The diagnosis may also involve another problem in the evaluation of this disorder, once the typical characteristics are related to those expected and socially reinforced. According to Millon, Millon, Meagher, Grossman and Ramanath, (2004; Millon, 2011), the traits present in the HPD, such as excessive attention seeking, seduction behaviors, and active search for friendships, are socially desirable. Moreover, studies suggested that the typical HPD symptoms are not related to measures of general psychopathology, as it happens with the other PDs (Nakao et al., 1992; Grant et al., 2004; Zimmerman, 2011).

In Brazil there are few instruments that assess pathological personality traits in a broad perspective (Carvalho, Bartholomeu \& Silva, 2010). Based on this scenario, Carvalho and Primi (2015) developed the Dimensional Clinical Personality Inventory (IDCP), a self-report instrument to assess pathological personality characteristics, based on the diagnostic criteria of DSM-IV-TR (APA, 2003) and on the clinical practice focused on personality disorders (Millon \& Davis, 1996; Millon et al., 2004; Millon, \& Grossman, 2007a; 2007b; Millon, Grossman \& Tringone, 2010). The IDCP consists of 163 items divided into 12 dimensions: Dependency, Aggressiveness, Mood instability, Eccentricity, Attention Seeking, Distrust, Grandiosity, Isolation, Criticism Avoidance, Self-sacrifice, Conscientiousness, and Impulsivity. This research focuses on the Attention Seeking dimension of the IDCP, that presents characteristics typically related to the HPD (Carvalho \& Primi, 2015), such as pleasure related to the excessive to get attention from others, using seduction and manipulation, active search for friendships, and relations are established quickly and superficially (Millon, 2011).

A study conducted by Abela (2013) compared the personality profile of 14 patients diagnosed with HPD to participants who presented a diagnosis of non-histrionic PDs ( $N=73)$, based on the IDCP. The results showed that the group with HPD did not presented scores above the mean standard deviation of the normative group. It was also found that the Grandiosity and Attention Seeking dimensions showed significant discrepancy between the groups of patients with HPD and with non-histrionic PD, suggesting that the former is distinguished from other disorders by the need for recognition and admiration. However, the results suggested that the histrionic group did not show higher scores, or indicative of personality pathology in the IDCP. This result corroborates the findings of Carvalho and Primi (in press) that showed no association $(r=-0.10)$ between the Attention Seeking dimension and the Neuroticism factor (five-factor model), and presented moderate relationship ( $r=0.56)$ with Extroversion, suggesting that the dimension of the IDCP is more associated with more adaptive traits rather than pathological ones. The authors also found a significant relationship between the Attention Seeking dimension and the HPD assessed by the facets of the NEO-PI-R.

The results with the Attention Seeking dimension indicated its adequacy, but also pointed out to the need for review. In this sense, Carvalho and Primi (2015) suggested recommendations for its reformulation, including the development of new items and the restructuring of some existing items, as there was a trend of more endorsement of the items in that dimension, so that people without diagnosis tended to present high scores, suggesting a low differentiation between individuals with pathological personality functioning patterns and those with healthier patterns. Based on that, Carvalho, Sette, Capitão and Primi (2014) developed a study with the purpose of reviewing the Attention Seeking dimension and verifying its psychometric properties, for which they adopted a two-step procedure: the development of new items for the dimension, and an empirical stage with data collection and analyses to verify the psychometric properties of the revised dimension. In the first stage, the researchers analyzed important 
models in the area, focusing on the pathological personality characteristics, such as the fifth edition of the DSM (APA, 2013); the dimensions of the Personality Inventory for DSM-5 ([DSM-5]; Krueger, Derringer, Markon, Watson \& Skodol, 2011), the dimensions assessed by the Shedler-Westen Assessment Procedure ([SWAP]; Westen \& Shedler, 1999); and the dimensions proposed by Anna Clark (1990), which are the basis of the Schedule for Nonadaptive Personality (SNAP). Based on these sources, a set of items was developed and those deemed the most suitable were selected for data collection, along with the original items and other instruments, relevant to the Attention Seeking dimension. Data found pointed out for the psychometric adequacy of the reviewed Attention Seeking dimension, but studies with clinical samples have not yet been conducted.

This research aims to investigate the clinical functioning of the Attention Seeking dimension and to establish a cutoff considering the diagnosis of HPD. For this purpose, three hypotheses have been developed: $\left(h_{1}\right)$ items must assess the most pathological levels of the latent construct more accurately $\left(h_{2}\right)$ people should be located at higher levels of the latent construct as they have more pathological personality traits related to the diagnosis of HPD; $\left(h_{3}\right)$ the dimension should discriminate groups according to the level of pathology in the HPD characteristics.

\section{METHOD}

\section{Participants}

The present study includes 1954 participants, aged between 18 and 90 years $(M=29.30, S D=11.38)$, 1212 women $(62.20 \%)$, mostly undergraduate students $(68.50 \%)$, accessed by convenience. The total sample was divided in three groups, outpatients diagnosed with HPD (Histrionic PD; $n=14$ ), outpatients diagnosed with other PDs (psychiatric; $n=168$ ), and people without known diagnoses (non-psychiatric; $n$ = 1772). Participants from the first two groups were accessed in a public psychiatric hospital, and those from the third group were accessed in private universities; all locations were within the state of São Paulo. Table 1 presents the demographics for the groups i.e., gender, age, educational level, psychiatric treatment, psychotropic use, and psychotherapy treatment.

Table 1. Demographic data according to groups.

\begin{tabular}{|c|c|c|c|c|c|c|c|}
\hline & \multicolumn{2}{|c|}{ Gender } & \multirow{2}{*}{$\begin{array}{c}\text { Age } \\
M(S D)\end{array}$} & \multirow{2}{*}{$\begin{array}{c}\text { Educational } \\
\% \\
\end{array}$} & \multirow{2}{*}{$\begin{array}{c}\text { Psychiatric } \\
\text { N } \\
\end{array}$} & \multirow{2}{*}{$\begin{array}{c}\text { Psychotropic } \\
\text { N }\end{array}$} & \multirow{2}{*}{$\begin{array}{c}\text { Psychotherapy } \\
\text { N }\end{array}$} \\
\hline & Male & Female & & & & & \\
\hline Histrionic PD & 13 & 1 & $28.12(10.46)$ & $42.90 \% \quad$ IG & -- & -- & -- \\
\hline Psychiatric & 66 & 102 & 40.45 (13.59) & $38.10 \%$ CHS & -- & -- & -- \\
\hline Non-patients & 659 & 1113 & $43.71(11.66)$ & $72.90 \% \quad$ IG & 62 & 32 & 197 \\
\hline
\end{tabular}

Note . CHS = complete high school; IG = incomplete graduation.

\section{Instruments}

The Dimensional Clinical Personality Inventory ([IDCP]; Carvalho \& Primi, 2015) is an instrument developed for the assessment of pathological personality that comprises 163 items on a 4-point Likertlike scale, where 1 stands for "has nothing to do with me" and four for "everything to do with me", with an average administration time of 25 minutes. The items cover the IDCP 12 personality dimensions, Dependency, Aggressiveness, Mood Instability, Eccentricity, Attention Seeking, Distrust, Grandiosity, Isolation, Avoidance of Criticism, Self-sacrifice, Conscientiousness, and Impulsiveness. We used both the revised version of the Attention Seek dimension (Carvalho, Sette, Capitão, \& Primi, 2014) composed by 13 items ( 3 original and 10 only in the revised version) and the original dimension items (Carvalho \& Primi, 2015).

\section{Procedures}

After submission and approval of the Research Ethics Committee (CAAE: C.A.A.E. 21992113.1.0000.5514), the data collection was conducted in a private university in the countryside of the state of São Paulo and in a public psychiatric hospital in the city of São Paulo. At the university, the instrument was administered was collectively, with duration of approximately 30 minutes in one session per class, in the classrooms. At the hospital, the application was collective.

Considering that 1.284 people answered only the original Attention Seeking items and 120 (from non-psychiatric) answered both instruments, with the original and the revised items, we used the equating procedure (Wolfe, 2000$)$, with all the 120 people as anchor and in 3 items ( $23 \%$ of total) as anchor as well, which seems to be adequate. Data were analyzed using the rating scale model (Wright \& Masters, 1982). A distinctive feature of this model is that the scalar intervals between points are deemed as relatively similar for all items. The difficulty parameter $b_{i}$ represents the location of item $i$, or the average intensity of the thresholds of an item. Items that represent extremes in the latent dimension are represented with high average thresholds because their thresholds are all located on the most intense 
theta levels. Item and subject model parameters were calibrated by the Joint Maximum Likelihood Estimation method implemented in the Winsteps software (Linacre, 2011). This calibration was performed considering original and revised items, so the parameters were estimated by all the participants, which is the purpose of the equating procedure.

The fit of the calibration was assessed by the fit indexes, infit and outfit, that were calculated for all the items and subjects. These values are directly proportional to the residuals that reflect differences between the observed and expected responses as hypothesized from knowledge of the model parameters, thus providing evidence of how well the model fits the data. Values greater than 1.3 indicate a misfit (Wright \& Linacre, 1994). Complementarily, we did the item-theta correlation, the general reliability ( $\alpha$ and Rasch) and the local reliability (Daniel, 1999).

After that, considering the study scope, we performed Wright map, item map, group comparisons (ANOVA) and ROC curve, trying to better understand the latent construct and also trying to establish the dimensions' cutoff. We point out that to the item map qualitative analysis we were based on the Elliott et al. (2006) recommendations.

\section{RESULTS}

Data were mainly run on the level of the items comprising the Attention Seeking dimension, but we also considered the four factors found earlier from the revised version of this dimension (Carvalho, Sette, Capitão \& Primi, 2014). To check the possibility of using the total score, we used the residual analysis, starting from the inferiority criterion of 2.0 eigenvalue in evidenced waste (Linacre 2011). The residue showed eigenvalue equal to 2.3 , which is marginally above the adopted criterion. Considering the value marginally higher against the high internal consistency of the group of items $(\alpha=0.74)$ and the value of the first eigenvalue $(4.10 ; 31.57 \%$ of the explained variance) obtained from the exploratory factor analysis (verified via SPSS) and the internal consistency $(\alpha=0.81)$ of the items making up this first factor, we decided to keep the analyses with the total group of items. We also investigated the functioning of response categories, for evidence of the suitability of the Likert scale used, as can be seen in Figure 1.

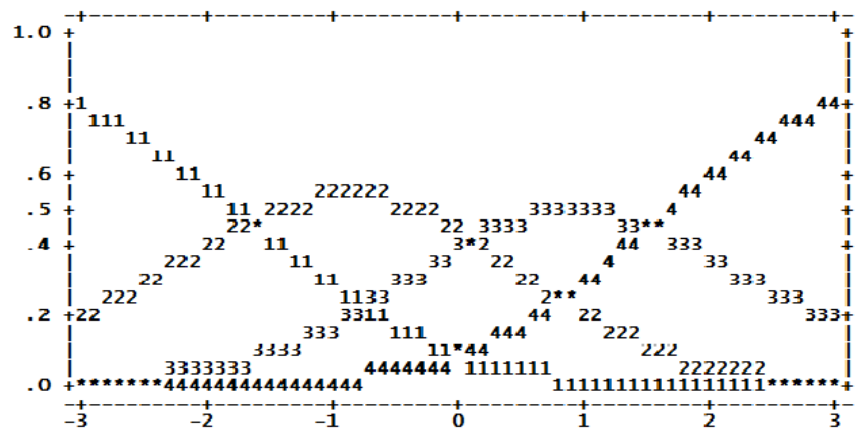

Figure 1. Categories of response according to the rating scale model

The level latent trait (theta) can be observed on the x-axis and, on the y-axis the probability of choosing a given category in relation to the theta. Figure 1 suggests the adequacy of the use of categories, as there are theta ranges where each category is more likely to be chosen, and consistently (i.e., lower levels of latent trait to numerically lower categories). Accordingly, the intersection between the first and the second category is equal to -1.75 , between categories two and three equal to 0.20 , and between categories three and four equal to 1.50. Further, in Table 1, we present the numbers of items, and in brackets, the number of the DMS-5 diagnostic criterion most related to each item, the descriptive statistics of items, such as level of difficulty, adjustment indices, the item-theta correlation, and reliability indices (both Rasch and Cronbach's alpha).

For a better understanding of Table 2, we should consider the descriptive statistics of participants presented in Table 3. The average of participants was -0.54 , suggesting that people tended not to endorse the items, and the average for the items was set at zero, as standard in Winsteps. In addition, almost every item (except for item 334) demonstrated a higher level of difficulty in relation to the mean theta presented by people, and some items $(n=5)$ present negative b parameter. Using Linacre and Wright (1994) as a criterion for infit and outfit indices (i.e., $\leq 1.3$ to be considered as appropriate), six items showed a discrepancy in the mathematical model, however the values were close to the established criteria. With regard to diagnostic criteria, it is observed that all appeared at least once represented by items; however, the criteria 2 and 8 are the most present and the 3 and 4, the least represented. Table 2 shows the summarized descriptive statistics about the participants and their theta fit indices (infit and outfit). 
Table 2. Descriptive statistics of the items in the Attention Seeking dimension

\begin{tabular}{lccccc}
\hline Items & $\boldsymbol{b}$ & $\boldsymbol{S . E}$ & Infit & Outfit & $\boldsymbol{r}_{\text {item-theta }}$ \\
\hline $362(7)$ & 0.56 & 0.14 & 1.51 & 1.43 & 0.78 \\
$342(2 ; 4)$ & 0.51 & 0.14 & 1.20 & 1.08 & 0.61 \\
$359(8)$ & 0.25 & 0.14 & 1.08 & 1.06 & 0.54 \\
$199(8)$ & 0.20 & 0.04 & 0.77 & 0.76 & 0.79 \\
$364(7)$ & 0.16 & 0.14 & 1.52 & 1.37 & 0.56 \\
$349(6)$ & 0.14 & 0.14 & 1.39 & 1.32 & 0.61 \\
$348(6)$ & 0.13 & 0.13 & 1.49 & 1.40 & 0.57 \\
$351(3)$ & 0.03 & 0.13 & 1.42 & 1.44 & 0.50 \\
$147(2)$ & -0.04 & 0.04 & 1.09 & 1.09 & 0.71 \\
$335(1)$ & -0.11 & 0.13 & 1.85 & 1.74 & 0.47 \\
$198(8)$ & -0.36 & 0.04 & 0.78 & 0.78 & 0.79 \\
$341(2)$ & -0.36 & 0.13 & 1.37 & 1.41 & 0.44 \\
$334(1)$ & -1.11 & 0.13 & 1.23 & 1.18 & 0.56 \\
\hline $\boldsymbol{b} \boldsymbol{M}$ (SD) & & & $0(0.42)$ & & \\
Infit $\boldsymbol{M}$ (SD) & & & $1.28(0.29)$ & & \\
Outfit $\boldsymbol{M}$ (SD) & & & $0.58(0.74)$ & & \\
Rasch reliability $(\boldsymbol{\alpha})$ & & & &
\end{tabular}

Table 3. Descriptive statistics of participants

\begin{tabular}{lccc}
\hline & Theta & Infit & Outfit \\
\hline $\boldsymbol{M}(\boldsymbol{S D})$ & $-0.54(1.29)$ & $0.89(0.83)$ & $0.89(0.83)$ \\
Min. & -4.23 & 0 & 0 \\
Max. & 3.36 & 4.40 & 4.54 \\
\hline
\end{tabular}

Although the mean latent trait of participants is lower compared to the b mean of items, the scores suggest that the sample is composed of people who agree with the Attention Seeking items, with variability in the levels of the latent construct. Also in relation to the participants, according to the infit and outfit indexes, it is possible to verify discrepancies between the values observed and those expected for estimating the latent trait (theta). However, these values tend to be acceptable (Linacre \& Wright, 1994), because the mean is less than 1.3 in all indexes. We also calculated the reliability index of the set of items in relation to the sample, using the rating scale, equal to 0.58 , and Cronbach's alpha, which was 0.74. This discrepancy occurs due to the way the two coefficients are calculated, so that in the case of internal consistency by rating scale, there is a greater impact of the ranges in the latent construct that are not covered by items, but present respondents. To examine the internal consistency, given the level in the latent construct, we also calculated the location precision (Daniel, 1999), as we can see in Figure 1.

In Figure 2, the $x$ - axis refers to theta (ranging between -1.5 and +1.5 ) and the $y$-axis to the reliability indexes.

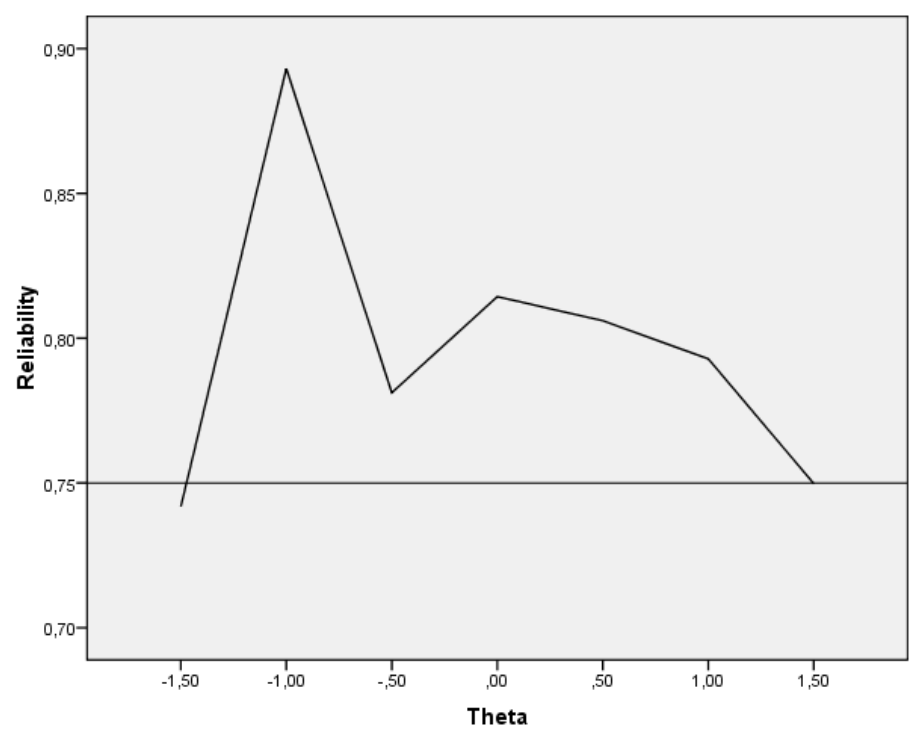

Figure 2. Local precision of the dimension. 
Unlike the traditional estimated internal consistency, which is a measure of reliability, disregarding the specific latent trait, in the local precision we may observe to which levels of the construct the measure is more reliable (i.e., presents less error). In this case, we verified levels higher than 0.75 for the ranges from -1.5 to 1.5 , and with elevation especially at ranges around -1 and zero. It is noteworthy that for the higher and lower ranges, from -1.5 and 1.5, we verified greater levels of error, because there are no adjacent items representing these ranges.

Continuing to deepen the understanding of the clinical dimension, we present the Wright map (Figure 3), based on the levels of difficulty of the items and theta of the participants. For the specific case of this map, considering the extension of the figure, we used sub-samples of all participants from the three groups $(n=370)$.

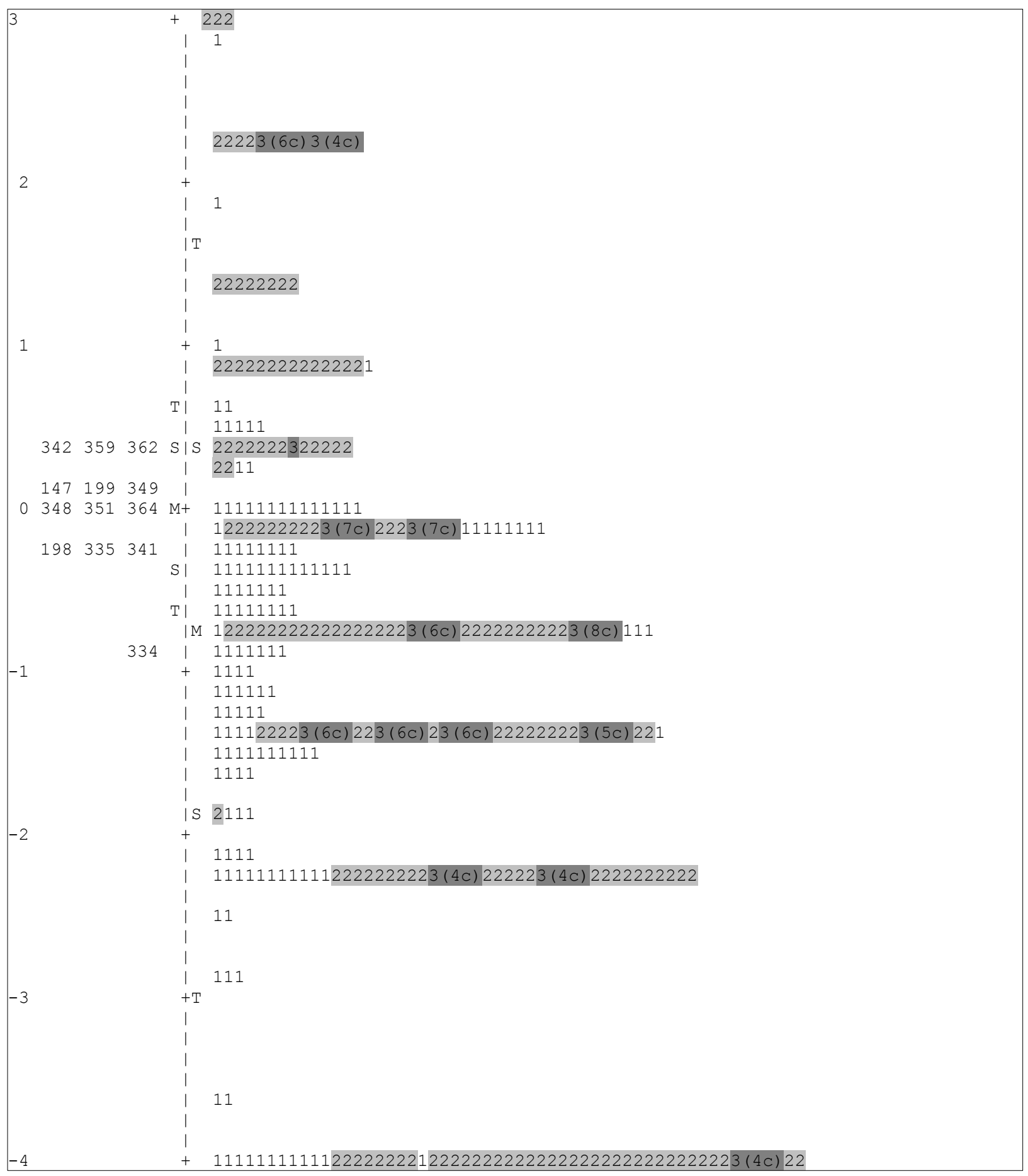

Figure 3. Item-person map of the Attention-Seeking dimension 
Figure 3 shows the map of items, showing the location of the people and the items represented by numbers and shades of gray. Non-patient participants are represented by number $1(n=188)$, psychiatric patients without a diagnosis of HPD by number $2(n=168)$, and patients diagnosed with HPD are categorized with the number $3(n=14)$. We verified that most patients (i.e., numbers 2 and 3 ) are located on the top of the continuum, and non-patients (number one) are presented further down, a fact that was expected.

The 14 patients with diagnosis of HPD were divided above and below the mean, i.e., seven patients are above the mean obtained by the participants, two of whom are located in the mean and the other seven are below the mean. In view of these results, discrepant form the expected; diagnoses from the group of psychiatric patients without HPD were also obtained, seeking to verify the existence of coherent patterns, hypothesized a posteriori. The data show that there are no subjects with avoidant PD at extreme levels (i.e. above zero) and there are few on the upper levels (between zero and -1). There are also no schizoid and schizotypal up to the value of -1 , and there is a predominance of borderline, histrionic, and dependent on extreme levels (up to zero). In addition, in the medium and low levels, the avoidant patients begin to show up and preponderate (from approximately -1 on the scale of the map). Complementing these data, Figure 4 shows the map of item (for both, both items of the dimension (top) and the total scores (bottom)). The items are displayed, from the bottom up, starting with the most endorsed and proceeding to the least endorsed by the participants. The number of each item and the response categories can also be verified in the figure.
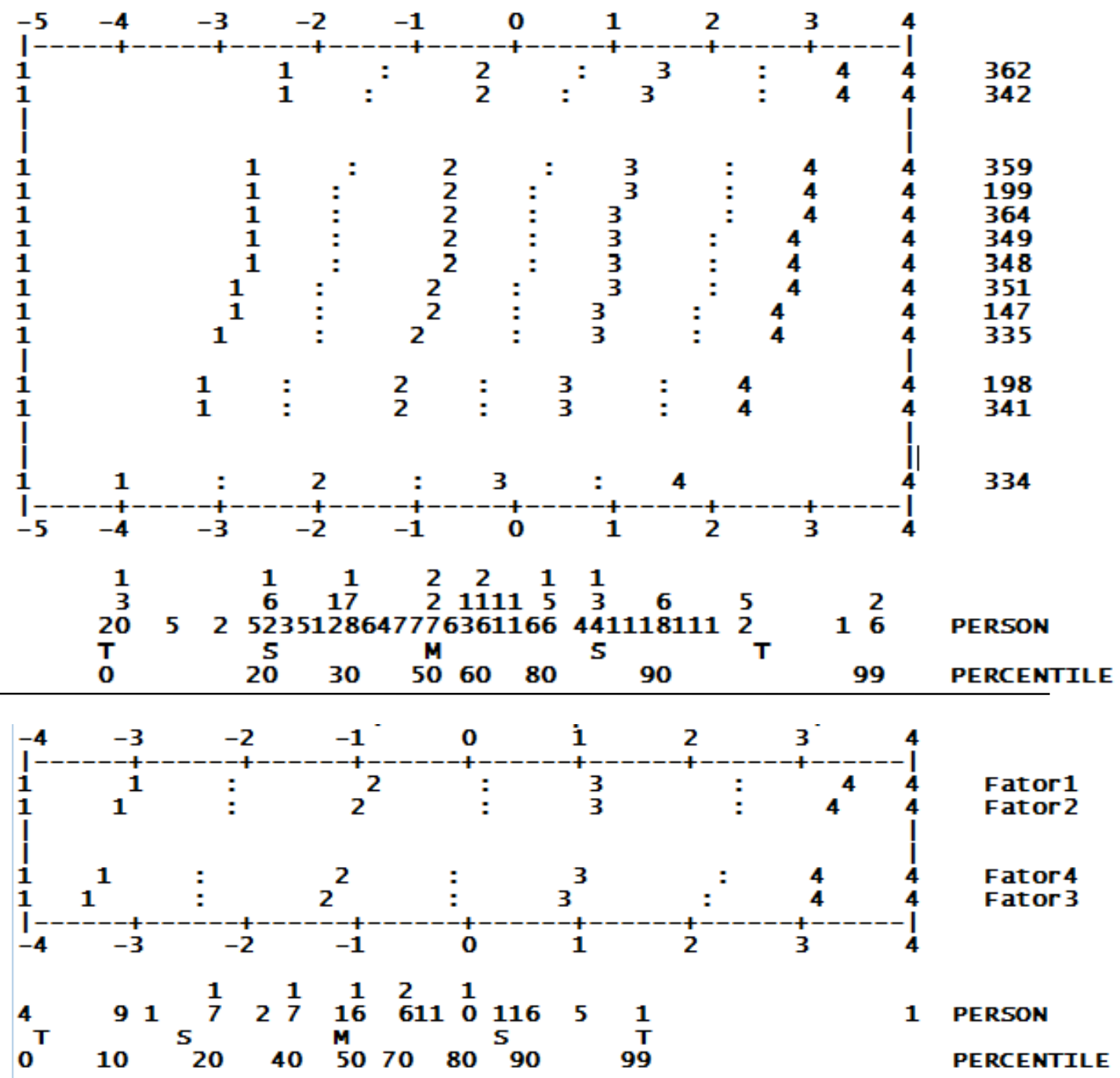

Figure 4. Map of items for the Attention Seeking dimension for items and total scores. 
Participants were concentrated between values -4 to +4 in the theta range. Furthermore, there is a greater concentration of people in the negative range, since a large part of the sample was made by the general population, but there are also subjects representing the higher ranges, i.e., more pathological of construct. In relation to the items, it turns out that the item 334, which deals with the desire of the individual to be the center of attention, was the most endorsed by the sample, followed by items 348 (referring to the intensity of the emotions) and 198 (which includes the facility to meet people and quickly establish a friendship). The less endorsed items were n. 362 (which deals with the need to know the opinion of people), followed by item 342 (related to using seduction to get what they want). Beside this, regarding the factors of the Attention Seeking dimension, at the bottom of Figure 4 we observed that Factor 3, called Attention Seeking, was the most endorsed. But the least endorsed factor was Factor 1 (Seduction and Manipulation).

Next, the groups were compared using ANOVA, which allowed to verify the discriminative ability of the Attention Seeking dimension according to the level of presence of diagnostic criteria for HPD, which can assist in establishing a cutoff for this dimension of the IDCP, along with the other data presented. Table 4 presents the descriptive data for the groups and Cohen's d.

Table 4. ANOVA for discrimination between the three groups.

\begin{tabular}{|c|c|c|c|}
\hline Groups & Mean & $S D$ & $d$ \\
\hline Non-patients & -0.70 & 1.62 & $\mathrm{~d}_{\text {non}}$-patients x patients $=0.38$ \\
\hline Patients & -1.38 & 1.95 & $\mathrm{~d}_{\text {patients } \mathrm{x} \text { histrionic }}=-0.24$ \\
\hline Histrionic & -0.93 & 1.76 & $\mathrm{~d}_{\text {histrionic } \mathrm{x} \text { non-patient }}=0.13$ \\
\hline$p$ & \multicolumn{2}{|c|}{0.17} & \\
\hline
\end{tabular}

Corroborating what was previously observed, the ANOVA showed significant difference between the groups $(p<0.001)$ but they did not differ in post hoc analysis. It is observed that patients with HPD presented means similar to those of participants from the general population, and non-histrionic psychiatric patients obtained a lower score in the dimension. Nevertheless, the magnitudes of the effect demonstrated that there is a significant distinction, especially between groups of non-patients and patients, and between patients and individuals with HPD. However, there was no significant distinction between the histrionic patients and non-patients.

As a last analysis, in the search for an ideal cutoff, we proceeded to the ROC curve for both situations. At first, as variable diagnosis we used the group of patients with histrionic functioning (HPD, borderline and dependent) versus patients with more pathological introspective patterns (schizoid, schizotypal and avoidant); the area below the curve (AAC) was equal to 0.80 (95\% CI 0.66 to 0.93 ), which is satisfactory (Braga, 2000), and the raw score in theta that seems to present the better sensitivity/specificity was -1.0 , with sensitivity of $68 \%$ and specificity equal to $84 \%$. In the second ROC curve analysis, we used as variable diagnosis the group of non-patients versus the group of patients without HPD. The area under the curve (AUC) was equal to 0.61 (95\% CI 0.55 to 0.66 ), which is unsatisfactory (Braga, 2000), and the raw score in theta that seems to present the best sensitivity/specificity relation was -1.6 , with sensitivity of $68 \%$ and specificity of $50 \%$.

\section{DISCUSSION}

We first verified the adequacy of items set according to dimensionality and response category criteria. Unidimensionality and a suitable functioning of all response categories were found. From this, the analyses considering the scope of the study were conducted.

Regarding the descriptive statistics of the items and participants in the Attention Seeking dimension, the mean presented by the participants was negative and the mean of difficulty for the items was higher than that presented by the participants. This finding is consistent as most of the sample was composed by people without known diagnosis of personality disorder. Therefore, we verified that participants tended to disagree with the items, which was expected, as the items in the IDCP were developed to assess pathological personality traits (Carvalho \& Primi, 2015), which tend not to be present in the general population (APA, 2013). This finding is considered an evidence of validity based on external variable for the instrument, since it can be inferred that higher scores on the dimension are indicative of more pathological levels of the personality characteristics.

In addition, we observed that the calculation of the reliability index of the items using the rating scale model and Cronbach's alpha presented discrepancy, probably due to the different ways of calculating each coefficient, so that in the first case the ranges with respondents and without items affect 
the reliability calculation more directly. Thus, we also calculated the local reliability (Daniel, 1999), in which people ranging from - 1.5 to 1.5 in theta scale seemed to be adequately evaluated, differently from subjects outside this range. According to these data, it is possible to hypothesize that for this range of theta, the set of items assesses the pathological traits typically related to the HPD with less error, because it contains the total set of items. Therefore, this result is favorable to the functioning of the investigated dimension, showing a lower level of error in the assessment of the desired range, and confirming our first hypothesis (h1).

In relation to the items of the dimension, only the item n. 334 ("There is nothing better than having people's attention.") presented location on the latent construct higher than the theta mean presented by people (e.g., Figure 4). The content of this item is related to the need to be the center of attention and to enjoy having people's attention, and it is possible that this trait is healthier compared to the remaining items of the scale, since it is considered socially desired (Millon, 2011). Complementary to this data, the fit indices showed some discrepancy (Linacre, 2011) for six items, but not enough to suggest their exclusion, since the content represented by these items is important for assessing typical characteristics of the HPD, which are not included in other items. In addition, other data such as theta-item correlation support the maintenance of these items.

Also in relation to the items, specifically regarding the DSM-5 diagnostic criteria for the HPD, criteria 2 and 8 were the most represented in the items, with content related to interacting with others, which is often characterized by seductive, provocative and inadequate behavior (criterion 2) and considering the relationships more intimate than they actually are (criterion 8). The less represented criteria were number 3 , which include the rapid change and shallow expression of emotions, and criterion 4, concerning the use of physical appearance to draw attention. Differently, in the study by Harford et al., (2012), the 8th criterion of the HPD was the most endorsed and the 4th, the least endorsed by the sample. So, we observed that the variation of difficulty in the diagnostic criteria represented by items in this survey was wider than the variation in HPD diagnostic criteria found in the study by Harford et al. (2012). This wider variation in the items is appropriate, since we intend to cover the largest possible range of the latent construct, but a small variation in diagnostic criteria is also adequate (such as demonstrated by Harford et al.), since different loads for the diagnostic criteria are not expected, i.e., there is no hierarchy of importance among the criteria.

In relation to the lower part of Figure 4, we noticed the factors included in the Attention Seeking dimension. On the one hand, the factor (3) Attention Seeking was the one containing more items endorsed by the participants. This factor includes items about the need to be the center of attentions, as well as the need to always being around people and having many friends. Corroborating the data found in this study and in literature, these are believed to be healthy characteristics, and are present and reinforced socially, which may explain the level of endorsement to the items of this factor (Nakao et al., 1992; Grant et al., 2004; Millon et al., 2004; Zimmerman, 2011). On the other hand, the factor (1) Seduction and Manipulation presented the least endorsed set of items, related to behaviors of manipulation to get people's attention, often using seduction. It is possible that the items assess these characteristics in a more pathological way, elucidating the tendency towards disagreement to this group of items. We should also consider the presence of social desirability in the first factor, as manipulation, for instance, is not a desirable behavior. Future research should explore deeply the variables impacting on the tendency to disagreement in this factor.

Complementary to these data, we verified the results on the map of items displayed in Figure 3. They did not confirm hypothesis $h 2$, in which patients, specifically histrionic, would be at a higher location on the map, once the characteristics compounding the Attention Seeking dimension are mainly related to this pattern, such as desire to be the center of attention, rapid and intense changes of expression, active search for friendships and use of seductive behavior to get attention from others (Carvalho \& Primi, 2015). However, many histrionic patients got lower scores than other psychiatric patients, including non-patients. At first this may indicate a malfunction of the dimension, but this discrepancy between expected and observed corroborates the data reported in the literature (Skodol et al., 2011), mainly because the frequency of HPD in large clinical samples is extremely variable. Future research should look for the reasons behind the observed pattern, again considering the possibility of social desirability presence, and also taking into account the low insight capacity and high difficulties at analyzing themselves in profound manners, both typically in HPD patients (Millon, 2011).

Another factor that can explain this functioning of HPD patients in the map items, is the fact that the characteristics in the diagnosis of HPD can also be found in other PDs and other psychiatric disorders (Skodol et al, 2011; Zimmerman, 2011), besides, these characteristics are socially desirable (Millon et al., 2004). Studies suggested that the typical HPD symptoms are not related to measures of general psychopathology, as it happens with the other PDs (Nakao et al, 1992; Grant et al., 2004; Zimmerman, 
2011). This may suggest that the criteria set out to compose the diagnosis of HPD, represented in the Attention Seeking dimension (Table 2) may be less related to pathological patterns and more to behaviors typically found in the population than it would be expected for symptoms of PDs.

In addition, Table 4 shows that non-histrionic psychiatric patients presented the lowest mean in the dimension, which was significantly different and with an expressive effect of moderate magnitude, compared to the means of histrionic and non-patients, which were not distinguished. This suggests that patients without pathological histrionic patterns tend to get low scores in the Attention Seeking dimension, i.e., moderate and high scores in the dimension may indicate either a healthier functioning or a pattern with histrionic characteristics.

We also highlight that we identified an initial pattern of patients diagnosed with histrionic, borderline, and dependent personality disorders as more frequent at higher levels of the construct when compared with other diagnoses, especially, schizoid, schizotypal, and avoidant. This finding corroborates the literature, demonstrating that the histrionic, borderline, and dependent disorders present common characteristics in the diagnosis, exemplified by Attention Seeking, present as the desire to be the center of attentions (HPD), need for affection and support (dependent PD) and fear of abandonment (borderline PD) (APA, 2013). Still, Skodol et al. (2011) mentioned that there are studies demonstrating the blurring of boundaries between the histrionic and the borderline PDs. The symptomatic overlap seems to be reflected in the data presently found and, such as reported by Skodol et al., it also seems that the data reflect the difficulty of distinguishing the HPD diagnosis from the diagnosis of other PDs. Nevertheless, there is consistency in the verified groupings: histrionic, dependent, and borderline on higher levels of the construct, and schizoid, schizotypal, and avoidant, on lower levels, suggesting evidence of validity for the dimension. Thus, the results confirm the $h 3$ hypothesis in part, which suggested that the dimension would discriminate the three groups in this study, which theoretically differ according to the severity of the pathological traits related to the HPD. This partial confirmation is considered as psychiatric patients were discriminated from the other two groups, but the other distinctions were not observed.

Finally, in relation to the objective of establishing a cutoff for the dimension, Figure 4 presents thetas around the mean of psychiatric patients $(-1.38)$, representing subjects that tend to disagree with all items, while thetas around the mean obtained by non-patients $(-0.70)$ and the mean for the histrionic patients (-0.93) are more related to the agreement of an item. The mean between histrionic and nonpatients did not differ significantly, suggesting a proximity between these patterns across the items in the dimension. In addition, it is noteworthy that the mean of the whole sample was -0.54 , with only one item below this point, and the range that better evaluates the latent construct is from -1.5 to 1.5 , with an increase especially in the ranges around -1 and zero. These findings seem to suggest that the agreement to one or more items of the dimension may indicate both healthy and histrionic (mainly present in the histrionic, borderline and dependent patterns) patterns, allowing us to consider, thus, a cutoff around -1 in theta. The data obtained by the ROC curve confirm the cutoff equal to -1 for distinguishing more histrionic patterns and more pathological introspective patterns (schizoid, schizotypal and avoidant). Moreover, considering the reported data, including the second ROC curve presented (i.e., non-patients distinguished from non- histrionic psychiatric patients), we suggest a cutoff at -1.6 to differentiate between healthier patterns and more pathological non-histrionic patterns.

The objectives of the present study were achieved, although some hypotheses have not been confirmed ( $h 2$ and $h 3$ partially), but data confirmed the difficulties encountered in the literature for the diagnosis of HPD. In relation to the applicability of the Attention Seeking dimension from a cutoff for clinical practice, the goal was reached with two possible cutoff, one to differentiate between patterns with more histrionic characteristics from patterns with more introspective pathological characteristics, and another for distinguishing between healthier patterns and non-histrionic pathological patterns. From the perspective of a preliminary study, we understand that the data presented indicate useful directions for the clinical practice in the assessment of pathological characteristics related to histrionic functioning using the investigated dimension.

However, some limitations should be highlighted. The number of the psychiatric sample was small, especially for individuals diagnosed with histrionic personality disorder without comorbidity. Also, the comorbidity with other personality disorders in the present sample can bring biases to the results, so it is important that future studies seek to replicate the study with a more significant number of patients without comorbidities. It should also be considered that although not all subjects responded to all items, they were all considered for the equalization procedure, which can bring some bias to the results. Finally, this study analyzed only one of the IDCP dimensions, but further studies should investigate the clinical functioning for the twelve dimensions of the instrument. 


\section{References}

Abela, R. K. (2013). Evidências de validade para o Inventário Dimensional Clínico da Personalidade (IDCP) com base nos perfis de participantes com diagnostico psiquiátrico. Tese de Doutorado. Universidade Federal de São Paulo, São Paulo.

American Psychiatry Association (APA). (2013). Diagnostic and Statistical Manual of Mental Disorders 5. Washington: American Psychiatry Association. Retrieved from http://www.dsm5.org/Pages/Default.aspx

Braga, A. C. S. (2000). Curvas ROC: aspectos funcionais e aplicações. Unpublished masters dissertation. Universidade do Minho, Braga.

Carvalho, L. F., Bartholomeu, D., \& Silva, M. C. R. (2010). Instrumentos para Avaliação dos Transtornos da Personalidade no Brasil. Avaliação Psicológica, 9(2), 289-298.

Carvalho, L. F., \& Primi, R. (2015). Development and Internal Structure Investigation of the Dimensional Clinical Personality Inventory (IDCP). Psicologia: Reflexão e Crítica, 28(2), 322-330. doi: 10.1590/1678-7153.201528212

Carvalho, L. F., \& Primi, R. (in press). Desenvolvimento e Investigação da Estrutura Interna do Inventário Dimensional Clínico da Personalidade (IDCP). Psicologia: Reflexão e Crítica.

Carvalho, L. F., Sette, C. P., Capitão, C. G. \& Primi, R. (2014). Propriedades psicométricas da versão revisada da dimensão necessidade de atenção do inventário dimensional clínico da personalidade. Temas em Psicologia, 22(1), 147-160. doi: 10.9788/TP2014.1-12

Clark, L. A. (1990). Toward a consensual set of symptom clusters for assessment of personality disorder. In J. N. Butcher, \& C. D. Spielberger (Orgs.), Advances in personality assessment. New Jersey: Lawrence Erlbaum Associates.

Daniel, M. H. (1999). Behind the scenes: using new measurement methods on the DAS and KAIT. In S. E. Embretson \& S. L. Hershberger (Orgs.), The new rules of measurement: What every psychologist and educator should know (pp. 37-63). Mahwah, New Jersey: Lawrence Erlbaum.

Elliot, R., Fox, C. M., Beltyukova, S. A., Stone, G. E., Gunderson, J., \& Zhang, X. (2006). Deconstructing Therapy Outcome Measurement With Rasch Analysis of a Measure of General Clinical Distress: The Symptom Checklist-90 -Revised. Psychological Assessment, 18(4), 359-72.

Grant, B. F., Hasin, D. S., Stinson, F. S., Dawson, D. A., Chou, S. P., Ruan, W. J., \& Pickering, R. P. (2004). Prevalence, correlates, and disability of personality disorders in the United States: Results from the national epidemiologic survey on alcohol and related conditions. Journal of Clinical Psychiatry, 65, 948-958.

Harford, T. C., Chen, C. M., Saha, T. D., Smith, S. M., Hasin, D. S., \& Grant, B. F. (2012). An Item Response Theory Analysis of DSM-IV Diagnostic Criteria for Personality Disorders: Findings From the National Epidemiologic Survey on Alcohol and Related Conditions. Personality Disorders: Theory, Research, and Treatment, 12, 1949-2715. doi: 10.1037/a0027416

Krueger R. F., Derringer J., Markon K. E., Watson D., \& Skodol A. E. (2011). Initial construction of a maladaptive personality trait model and inventory for DSM-5. Psychological Medicine, 8, 1-12. doi: 10.1017/S0033291711002674

Linacre, J. M. (2011). Winsteps ${ }^{\circledR}$ (Version 3.72.3) [Computer Software]. Beaverton, Oregon: Winsteps.com. Retrieved from http://www.winsteps.com/

Linacre, J. M, \& Wright, B. D. (1994). Reasonable mean-square fit values. Rasch Measurement Transactions, $8(2), 370$.

Millon, T. \& Davis, R. D. (1996). Disorders of Personality DSM-IV and Beyond. New Jersey: Wiley.

Millon, T. Millon, C. M., Meagher, S. Grossman, S., \& Ramanath, R. (2004). Personality Disorders in Modern Life. New Jersey: Wiley.

Millon, T., \& Grossman, S. (2007a). Moderating severe personality disorders. New Jersey: John Wiley \& Sons Inc.

Millon, T., \& Grossman, S. (2007b). Overcoming resistant personality disorders. New Jersey: John Wiley \& Sons Inc.

Millon, T., Grossman, S., \& Tringone, R. (2010). The Millon Personality Spectrometer: a tool for personality spectrum analyses, diagnoses, and treatments. In T. Millon (Org.), Disorders of Personality: introducing a DSM/ICD spectrum from normal to abnormal. New Jersey: Wiley.

Millon, T. (2011). Disorders of Personality: introducing a DSM/ICD spectrum from normal to abnormal. New Jersey: Wiley.

Nakao, K., Gunderson, J., Phillips, K., Tanaka, N., Yorifuji, K., Takaishi, J., Nashimura, N. (1992). Functional impairment in personality disorders. Journal of Personality Disorders, 6, 24-33. 
Skodol, A. E., Bender, D. S., Morey, L. C., Clark, L. A., Oldham, J. M., Alarcon, R. D., Krueger, R. F., Verheul, R., Bell, C. C., \& Siever, L. J. (2011). Personality Disorder Types Proposed for DSM-5. Journal of Personality Disorders, 25(2), 136-169. doi: 10.1521/pedi.2011.25.2.136

Zuccolo, P. F., Corchs, F., \& Savoia, M. G. (2013). Psicopatologias e o conceito da Personalidade. In L. F., Carvalho, \& R. Primi (Eds.), Perspectivas em psicologia dos transtornos da personalidade (8-23). São Paulo: Casa do Psicólogo.

Zimmerman, M. (2011). Is There Adequate Empirical Justification for Radically Revising the Personality Disorders Section for DSM-5?. Personality Disorders: Theory, Research, and Treatment. Advance online publication. doi: $10.1037 / \mathrm{a} 0022108$

Widiger, T. A. (2011). A shaky future for personality disorders. Personality Disorders: Theory, Research, and Treatment, 2(1), 54-67. Doi: $10.1037 / \mathrm{a} 0021855$

Westen, D. \& Shedler, J. (1999). Revising and assessing Axis II, Part I: Developing a clinically and empirically valid assessment method. American Journal of Psychiatry, 156, 258-272.

Wolfe, E. W. (2000). Equating and item banking with the Rasch model. Journal of Applied Measurement, 1(4), 409-434.

Wright B. D. \& Linacre J. M. (1994). Reasonable mean-square fit values. Rasch Measurement Transactions, 8(3), 370.

Wright, B.D., \& Masters, G.N. (1982). Rating scale analysis. Chicago: MESA.

Historial do artigo

Recebido $21 / 07 / 2015$

Aceite $\quad 09 / 05 / 2016$

Publicado 06/2016 